\title{
Digital Text through Hot Potatoes in Supporting Online Learning in Digital Society
}

\author{
Syamsiah Depalina Siregar ${ }^{1)}$, Jasmienti' ${ }^{2}$, Dian Anggraini ${ }^{3)}$ \\ ${ }^{1)}$ STAIN Mandailing Natal, ${ }^{2)}$ IAIN Bukittinggi, ${ }^{3)}$ Universitas Putra Indonesia YPTK \\ email: syamsiahdepalina@ stain-madina.ac.id ${ }^{1}$, jasmienti@gmail.com² \\ diananggraini.unp@gmail.com ${ }^{3}$
}

\begin{abstract}
Pandemic era stressed the lecturer to create innovative learning process. The article aimed to show up the benefit of hot potatoes in online learning. Hot potatoes is one of applications which consists of 6 tools in making interactive exercises. They are J Quiz, J Cross, J Cloze, J Mix, J Match, the masher. It helps lecturer managed exercises based digital text. It can used on offline. This article used research and development by Addie. There are five steps in Addie model. They are Analysis, design, develop, implementation, and evaluation. Data found that hot potatoes supported students in learning process. They more enjoy in completed the exercises on hot potatoes. Digital text used is decreasing the using of hardcopy, it help students saving the cost.
\end{abstract}

Keywords: digital society, digital text, hot potatoes, online learning

\section{Introduction}

Corona virus is the term in this era. It is not in Indonesia's problem but international also. World Healthy Organization (WHO) South-East Asia Region reported over 600.000 cases increasing update 6th September. Approximately twenty seven million Covid-19 and nine hundreds billion deaths as denounce from WHO update (WHO, 2020). Although the pandemic show up the high spread, the learning process should must go on. (Moorhouse, 2020) states that the educators must forced in conducting online learning in minimazing the spread of covid - 19. It should be noted that the above does not argue that all instructional approaches will work for everyone, nor that there is evidence beyond anecdotes supporting their effectiveness. In fact, more research is needed on online instruction replacements for face-to-face lessons. In addition, training should be provided to Initial Teacher Education tutors, so that they are prepared to deliver online courses in the event of a health emergency.

Online learning is the solution for this era. Educators forced to create and give innovation in learning class. Many aplications can support the online learning. Technology is needed in supporting the learning process (Dočekal \& Tulinska, 2015). The educators must avaliable in follow the development of the technology itself. Belending techlogy is the one choose in creating the learning process. The educators blend the conventional activities with the activities based technology (Siripongdee, Pimdee, \& Somki, 2020). In other case (Budhwar, 2017) says that technology be apart of education itself. They walk together in gettting the great learning class. We can separated them, must follow them.

The one of the apps that can use is Hello English. It is an apps get free from the playstore. The students ordered to downloaded it and be independent learner. The lecturer guide them relate to the topic, reminder them to follow every lesson, and always ready in giving solution when the students facing the problems. The result of article showed that the students got new experience when use Hello English, they 
can battle with their friends from outside, it can be use offline and online. When they use in offline, it made the students got low cost. In online they can get new friends and can discuss directly. The more unique, it has report in every lesson (Siregar, Sari, \& Simamora, 2020).

The other result from Nepal told that E learning offers a good opportunity to continue one's education while also supporting economic development in developing countries like Nepal. This will

help to solve the actual problem that teachers and students face when conducting online classes, which in turn helps to improve the overall effectiveness of the education system. (Subedi, Nayaju, \& Subedi, 2020).

Many ways have educators did to success the learning process. Online learning with many tools or apps. The apps can offline and online based on the capacity and the features. The all Online learning use digital text. (Wiberg, 2015) put on her article that the habits and attitudes of students may be critical, an online textbook that is made digitally is much better than a print book when it comes to studying. Many, if not most, people who prefer to read on screens are paper readers from the beginning, and since the existing application interfaces fail to meet the inherent challenges of screens when it comes to spatial landmarks, we will always be forced to read on paper. She informed that digital text in screen paper is help some students to get the material. It is based on their usual activity with the text in digital form.

In other cases (Rossa, Pechenkinab, \& Aeschli, 2017) explained that a critical literature review that uncovers findings on how to apply digital text in education, with specific recommendations for the use of digital text for educational impact. Educational resources that are available to students feature a variety of digital texts, and evolving technologies present new opportunities and affordances for student learning. Digital-texts are examined by academic researchers in a variety of different ways, including in how they assist teaching and learning practices such as learning outcomes such as retention of information and the ability to provide feedback. Additionally, we review diverse techniques like note-taking, annotation, bookmarking, hypertexts, and highlighting with respect to e-text tool usage. Reinforcing the existing dichotomy pitting print-based ('traditional') texts against e-texts is widespread among studies on evidence-based e-texts. We recommend refocusing on various aspects, such as how knowledgeable students are about their options for accessing learning materials and whether they are given the proper training in order to take full advantage of the capabilities of e-texts.

Digital text is a digital representation of written text. Knowledge Representation is central and the supporting typographical elements can differ in different digital representations. In This definition, it does not include other forms one might see as text, such as animations or videos (Os, 2014). On the other hand, another author remarked that reading an academic text in a paper format can be difficult, and reading it online only adds to the challenge. With the increase in adult learners using digital texts for academic purposes, educators have the opportunity to teach students how to comprehend and think critically when reading these texts. It is not unusual to find articles and ideas for teaching digital reading to elementary or secondary students, but finding resources for teaching adult learners how to interact effectively with digital texts is a bit more difficult. Thankfully, the reading abilities that foster active or deep reading for younger learners can also be applied to adult learners. Additionally, the same tools used to engage with print text, such as annotating, questioning, and summarizing, work just as well with electronic text (Julian, 2018).

The writer wants to develop digital text through an application called Hot Potatoes. It hopes to help the educators to accomplish the process of learning in the age of pandemics. Stewart Arneil, Martin Holmes, and Hilary Street each introduce with "Hot Potatoes." Windows and Macintosh were used. The Half-Baked Software program Hot Potatoes, currently produced, was designed to allow teachers to make interactive, Web-based exercises that can be accessed by students using a standard Web browser on any Internet-capable computer. The exercises work using HTML and JavaScript; however, one does not need to know these languages to complete them. Instead, teachers use exercise templates from the program to produce exercises on web pages that can then be uploaded to a server where students can access them. Hot Potatoes' six Web-based exercises can be used separately or as components in a sequence of related 
tasks. Students can provide feedback and clues to one another in advance so that they can self-correct their work. By using Hot Potatoes, the teacher is also able to specify an email address where the student scores are sent. Even if no knowledge of Web design is required to create Web page exercises, teachers with this knowledge have greater flexibility by customizing the materials in code. (Winke \& MacGregor, 2001).

A researcher from Manchester also told that Hot Potatoes has been utilized by educational practitioners (both teachers and lecturers) to assist in classroom learning from various cross-sciences. This article explains how to use Hot Potatoes software to create interactive games or crossword games to support the study of hadith sciences. This article concluded that the creation of games with this Software to support the learning of hadith science has been very able to be done, even further developed (Jervis \& Steeg, 2006).

Another article noted that students could use hot potato to monitor their own learning. "Hot Potatoes" as a useful design resource for developing customized exercises and didactic units for reading comprehension courses. Teaching English as a Foreign Language includes the concept of autonomy (TEFL). In particular, the authors will talk about learner autonomy as a desirable characteristic in students while they are in the process of learning how to read. Additionally, teacher autonomy, which is often overlooked, will be covered. reading comprehension and learning styles will also be covered. Finally, the authors will make general statements about reading instruction, discussing some basic features of "Hot Potatoes," and giving examples of how to use this software in reading comprehension courses (Pablo \& Giannina Seravalli Monge, 2014).

In this occasion, the writers wanted to develop digial text trough the using of application Hot Potatoes. The writer use it as a medium in supporting the learning procees. Digital text is approptiate with the society nowadays. They are a digital society.

\section{Methods}

This research adopted research and development study from ADDIE model. According to Albion cited in (Shariffudin, 2007) This study implemented the procedural model, which was designed to aid in the development of hot potato-based teaching and learning materials for English second semester. To explain the ADDIE models, one may say they look like this. Analysis was the first step. Analyzing learning processes and media of learning was done using questionnaires for students and interviews with students at 2nd semester in Tadris Bahasa Inggris Stain Mandailing Natal. Design was the second step. When developing a new course, there are several processes that designers use, such as formulating a set of learning objectives, analyzing different learning theories, and mapping out the workflow for course materials that are about to "heat up." Although it covered some processes (e.g. content development, storyboard development, and courseware development), the third stage is primarily in the process of developing content. The final stage was actually implementation. hot potato-based materials were sent to 35 students in this stage. In order to be usable, the students provided reassurances about the suitability of using hot potato-based materials. Finally, we reached the evaluation stage. To determine which plastics were most suitable for a hot potato-based product, the purpose of the evaluation was to get the evaluation on hot potatoes. Each item was evaluated by media-materials experts and a language expert.

\section{Result and Discussion}

This study looks at the order in which the research questions were asked. (1) What does hot potatobased digital text do in supporting online learning?, (2) What does the design of hot potatoes-based digital text do in supporting online learning? (3) How is the development of digital text based on hot potatoes assisting online learning? (4) Is hot potatoes-based digital text useful in supporting online learning? The process of developing potatoes-based materials for second semester of 2019-2020 academic year students with ADDIE is discussed in this study. Based on the questions posed by the research. 
Questions 1: What does hot potato-based digital text do in supporting online learning?

In this study, need analysis section was conducted to locate the students' needs in the second semester of Tadris Bahasa Inggris. In the analysis stage, questionnaires and informal interviews were used. A questionaire was employed to gather the relevant information pertaining to using media in learning, availability of media-based resources in learning, student preferences for learning, and various learning activities. After doing the questionnaire, interviews were conducted to make sure students' responses were correct or to find out if the data on the questionnaire was correct. This survey indicates that $54 \%$ of students have their own computers or laptops. Everyone in the class was able to use a computer. Aspects like these could serve as a basis for developing multimedia-based learning materials for teaching and learning English. students are holding devices with Android-based dictionaries for 41\% of students, and $90 \%$ of students are using e-dictionaries and printed dictionaries to learn English. To collect the information as to why they needed to bring an English dictionary, the interviews were conducted. Based on the interviews, it appears that students of SMK Negeri 1 Balai still needed vocabulary improvement. The findings demonstrated that students were still in the midst of a vocabulary deficiency. Resources with hot potato-based materials must be planned in such a way that language enhancement activities for students of Tadris Bahasa Inggris are supported. Based on the questionnaire, $64 \%$ of students did not have an application for learning English on a computer. So, only about 35\% of students (of this total) have an application for learning English on their computers. In other words, the aforementioned students of Tadris Bahasa Inggris still had an issue with missing English learning resources, especially multimedia-based resources. The students only had workbooks, power point slides, and e-books on their computers. The interviews were also to gather the information on their current workbook and ebooks. Interview results showed that the majority of students believed that they required interactive learning materials in order to learn English. 87.1\% of the students also required interactivebased materials, such as quiz (77.4 percent ). The materials of the $93.5 \%$ of students needed animations or pictures. There were $87 \%$ of students who said they were unmotivated to learn English using only workbooks because they could not get feedback directly.

The second section dealt with task-topic analysis on English curriculum on Tadris Bahasa Inggris in order to find a hot potato-based topic that could be used in various materials. The purpose of this research was to uncover the relevance of English curriculum with hot potatoes-based materials. This was one of the reasons since curricula could not be completely converted into content of hot potatoes-based materials. Next, the aim was to define and designate the overall objectives of the activities in hot potatobased materials. In order to meet the needs of the students, all of those analyses were done. Finally, it should be noted that assessment of need addresses two distinct concerns. The first facet was the students' requirements for multimedia-based resources. Materials must be interactive and based on activities such as games or quizzes. Additional materials must be designed to meet individual or group learning requirements. It must also ensure colorful displays and allow for students' feedback and corrections. aspect number two: conducting an English curriculum task-topic analysis in Tadris, Bahasa Inggris. The topics and objectives that could be developed using Hot Potatoes-based materials were established as Hot Potatoes-based materials relevant to the English curriculum.

Question 2: What does the design of hot potatoes-based digital text do in supporting online learning?

The instructional materials was created with various things taken into consideration, including an overview of learning theories and a summary of results from a demand analysis. Those aspects were discussed as follow. The overviews on learning theories mean to get the perspectives on human learning process. First overview had been on behaviorism theory. This theory points that to form positive behavior in learning, there must be benefits for correct response and punishments for wrong approach. In the design process of hot potatoes-based materials, the implementation of moral guidelines in hot potatoesbased materials was forms of scores and corrections for each response on the quiz activities. Basically, in 
summary, students could directly gain the results from quiz activities. The students also could get feedback effects or correction for the wrong answers or negative responses on the quiz activities. Second outline was on cognitive theory. This view asserts that learning process must be in line with the cognitive process. It means working memory on human brain has limitation in holding information for a limited duration, meaningful learning where students must construct the knowledge by their own efforts and experiences. Hot potatoes-based materials marked the cognitive theory since hot potatoes-based activities provide enough duration for students working memory to remember words or vocabulary. Hot potatoesbased materials activities allowed interacting with the quiz activities. This process could support students to construct the knowledge by experiencing it. They also could construct their knowledge of English from the feedbacks or corrections that were provided in the quiz activities. Third overview was also on constructivism theory. The theory shows that learning is a process of constructing knowledge that combines the new information with the existing knowledge and experiences in their environment. In the design of hot potato-based materials, constructing students' English knowledge is apparent by activities like filling the gap, and matching quiz pictures..

Some of the students will also be able to learn some grammar rules, certain expressions, and vocabularies as they take the quiz. As a result, it is easy to determine whether or not a quiz is too difficult for students to complete if they find it. They are also given the feedback once they have completed the quiz. All those activities are valuable in that they will help students to use their previous knowledge and acquire new knowledge. The fourth approach to educational technology was multimedia theories; multimedia can incorporate multiple attributes in learning, such as words, pictures, or animations. For a rewarding educational experience, students should choose program elements that incorporate attributes from more than one group. Students get knowledge, enjoyment, and an educational experience all rolled into one when the state uses tools like graphics, interaction, and skill building to infuse information in the classroom. In terms of design, hot potatoes-based materials provide numerous advantages. Students who have used the strategy in the past have experienced significant boosts in motivation and engagement with their studies. It is an effort to help students remember and practice material better because it includes pictures, interactions, and learning challenges. Furthermore, when designing a process, it was also necessary to focus on the transformation of the objectives derived from a previous stage of need analysis into a set of learning objectives. The learning objectives were organized to enable the development of materials projects based on the Hot Potatoes framework that is relevant to students. An educational design to accomplish the learning objectives was created by utilizing activity materials using a hot potato concept (see table 1). For the objectives of this assignment, you may want to conduct some of these activities in hot potato-based materials. In the first place, the activity in which students have to select the correct answer from a selection of possible answers is called a Quiz or Multiple Choice activity. As you are adding texts or images to your project, you have the ability to also include a headline. Also, the activity that students must match between options a and $\mathrm{b}$ is activity that needs to be matched. Third, mixed-up activity is work that students must accomplish, such as arranging words into a correct sentence. The fourth point to make is that Gap-fill activity is a task where students have to use correct words or expression to complete the task. Lastly, crossword puzzles offer an opportunity for students to build a foundation of correct words by identifying clues and applying those words to the grid.

Question 3: How is the development of digital text based on hot potatoes assisting online learning?

To provide coverage, these processes involved development stages such as content development, storyboard development, and courseware development. The contents of the item could include different elements, such as interactive content or simulation. As a process, this included the selection of activities that were suitable for use in hot potatoes-based materials. Additionally, the images and animations that were gathered during this step were compiled. Materials that can be manufactured using potatoes as a foundation can be drawn from many different sources, including books, the internet, and pictures from the real world. In addition to creating the objectives, the instructions, multimedia contents, and quiz activities, 
this stage also created the processes of creating the objectives, the instructions, and the feedbacks. The second step in the creative process was storyboard development. Storyboarding is a way of depicting the scenes of a film in visual form. In this study, storyboards can be implemented in the form of screen slides. However, given the previous design process, the storyboard was developed to follow the layout (blueprint) in some respects, but also to include some adjustments that could be made. This was the last process we went through. It is at this stage that authorsing tools are required to bring all the elements into finished products of learning. In this case, the authoring tool used was the masher. It is parts of the Hot Potatoes program that are used to integrate the activities within a course unit.

Question 4: Is hot potatoes-based digital text useful in supporting online learning?

It appears that a few different topics were discussed - and responded to - on hot potatoes-based materials due to the illustration above. The various aspects considered included: The first response was to apply hot potatoes-based materials to the students' laptops. There were $100 \%$ respondents who agreed that laptop components which incorporated hot potato-based materials were a good idea. Second response had to do with working with/ using hot potatoes-based materials. When it came to operating hot potato-based materials, $58 \%$ of respondents marked that these are simple to use. Students could recognize the objectives and the instructions on hot potatoes-based materials when asked to recall which two additional ingredients go into the rubs used in hotpot cooking. In light of these responses, then the forth response, all of the students (100\% of respondents) responded that they could interact actively with various quiz activities in hot potatoes-based materials. The fifth response mentioned that, as it turned out, there were $100 \%$ of respondents who were capable of and comfortable getting and applying the feedbacks or corrections for the quiz activities. According to the sixth response, which had $92 \%$ of respondents, hot potatoes based materials is a form of study and workbook that allows one to properly and safely engage in quiz activities. When $78 \%$ of the participants affirmed that they could find attractive and colorful displays on hot potato-based materials, they all agreed that there were $83 \%$ of respondents who could identify colorful and attractive displays on hot potato-based materials. Among the 58\% of respondents, there were $46 \%$ who answered in the affirmative to the question, "Have you used hot potato-based learning materials in order to study English?" At the end of the day, the students showed a lot of interest (with an $80 \%$ positive response for total responses) in the hot potatoes-based digital text that helps with online learning.

\section{Conclusion}

Although teaching reading comprehension is always a demanding task for language teachers, it can be accepted that they will always have to put in the work. Even though it is true that the use of free authoring tools such as Hot Potatoes does have the benefit of opening new doors for teachers as they are able to create and design materials tailored to their students' needs, it does mean that learners and teachers have lost some of their autonomy as a result. While discussing the beginning of this article, it should be noted that this is not about making completely new teaching methods for teaching reading comprehension; older, conventional reading comprehension exercises can be applied to the formats that Hot Potatoes offers and are more appealing to and useful for students. in addition, the authors would like to note that using Hot Potatoes in language courses has numerous benefits, and the following are a few of them:

1. Motivation is increased due to the ability to use technology and the use of various learning styles are facilitated.

2. It is possible to make the activities for Hot Potatoes in HTML format more customized, as the files that go into their activity creation are exported in the process. Unfortunately, there are tutorials on the Hot Potatoes website that can assist with this. 
3. In relation to the previous idea, with some basic HTML programming skills, Hot Potatoes allows for the use of video and audio files, so it could also be used for instructing students' listening comprehension skills in oral courses.

4. It will be easier to commit to learning something if the course follows a nontraditional approach that is adopted by the teachers.

5. In Hot Potatoes, learners' autonomy is boosted because creating in students the feeling of being in control of their own accomplishments with a sense of challenge and appreciation of their level of achievement results in constructive criticism.

6. The increased freedom that comes with the use of an innovative teaching tool is well received by teachers who can now use Hot Potatoes to come up with innovative and custom materials for their students.

7. With the use of this software, teachers can engage reluctant readers by incorporating a wide range of exercises into their curriculum, each of which includes assignments of varying difficulty, all of which requires differing levels of comprehension of a written text in order to finish.

8. The authoring tool is completely free of charge, and thus the use of it doesn't result in an out-ofpocket expense. The installation of Microsoft Services and Apps for Business is simple and it does not require users to adhere to a specific operating system as it can be used with Windows, Mac, and Linux (Half-Baked Software Inc., 2013).

9. Teachers and other internet users can find several communities and teachers who have tutorials, new ideas, and technical support to help teachers learn how to use Hot Potatoes. In addition, there are multiple communities and teachers on the internet who offer sample materials to be used as examples to create new activities.

10. The content of the knobs and scroll bars in any Hot Potatoes task can be revised comfortably, which means that users can easily design activities in different languages. When use Hot Potatoes, it can work with Unicode data. (Half-Baked Software Inc., 2009). The solution to this means that new exercises can be created for Asian languages, because Hot Potatoes lets the characters used in these languages be used.

11. Students can insert a "onscreen keyboard" into JQuiz and JCloze, which lets them write characters not in Latin without having to re-learn keyboard shortcuts if they are working with a computer with a different keyboard language configuration.

12. As the technology associated with e-mail and digital activities is less reliable, or in cases where a class teaching method is preferred, users are given the option to convert their digital activities into printed handouts should such an event occur.

The authors want to give an objective review of Hot Potatoes because they would also like to point out some flaws that come from using it:

a. Hot Potatoes gives immediate feedback to the students, with the possible answers predeter-mined by the designer of the activity, and students will sometimes complain that an answer they know is correct was considered incorrect by the program. When one thinks about it, it is quite important to remember that Hot Potatoes can only perform the task it has been programmed to perform; it cannot think on its own. As a result, it will never take the place of a teacher's critical mind.

b. There are still some issues to address with Hot Potatoes. It's common after exporting an activity to HTML format for sections of text to be duplicated. This can be especially problematic with Jcloze, and so the activity must be outsourced to HTML then.

c. When it comes to gap-fill activities in which the students must use apostrophes, there is a possibility that typographical signs such as 'c', 'l', 's', and 'a' will not be detected by the program. While the students are frequently using single quotation marks instead of apostrophes, which Hot Potatoes will misinterpret as different symbols and mark the answers as incorrect, this can also be 
attributed to the fact that students are using single quotation marks instead of apostrophes, which Hot Potatoes will interpret as different symbols and deem the answers containing them incorrect.

d. Some students will tell the teacher that the package was corrupted if they download a package with a Hot Potatoes unit, and the teacher would not realize that the student needed a packer program to unzip the unit because the student forgot that this software is required.

e. With regard to opening Hot Potatoes activities with Internet Explorer, we don't recommend this approach, as it has the effect of blocking the activities from appearing, as a security measure, and the students will have to allow the blocked content every time they start a new activity, which is frustrating and unnecessary if they are unaware of how to allow the content. Despite this, the majority of other browsers (if not all) will not trigger this annoyance.

When the lecturer incorporate videos into Hot Potatoes activities, the videos might not play on some computers because a certain plug-in is missing, and if the students don't know how to install it or don't have the necessary user rights, the activity will be completely useless.

\section{Acknowledgments}

We thankful to Allah Swt that has given chance, healthy for us to finishing this article, and solawat and salam we give to our prophet Muhammad Saw that bring us from the darkness to the brightness as we facing up nowadays. Thanks to the all committees of ICOLP that give us chance to deliver our research.

\section{References}

Beatrice, G. (2011). E-learning methodologies: A guide for designing and developing e-learning courses. Rome: FAO of the United Nations.

Budhwar, K. (2017). The role technology in education. International Journal of Engineering Applied Sciences and Technology, 14(2), 55-57.

Dewiyani, S. (2015). Improving students soft skills using thinking process profile based on personality types. International Journal of Evaluation and Research in Education (IJERE), 4(3), 118-129.

Dočekal, V., \& Tulinska, H. (2015). The impact of technology on education theory. Procedia Social Behavior Science, 27(2), 3765 - 3771.

Giganti, P. (2007). Why teach problem solving, part I: The world needs good problem solvers!. ComMuniCator, 31(4), 15-16.

Jervis, A., \& Steeg, T. (2006). Personal ICT skills 9 using hot potatoes. Education (November). p. 26.

Julian, S. (2018). Digital text and reading strategies. Tips and Trends, Spring 2008.

Moorhouse, B. L. (2020). Adaptations to a face-to-face initial teacher education course 'forced' online due to the COVID-19 pandemic. Journal of Education for Teaching, 13(3), 23-27.

Os, M. V. (2014). Digital text in education. Book and Digital Media Studies, 8(3), 10-19.

Pablo, J. P., \& Giannina Seravalli Monge, G. S. (2014). Considering the use of hot potatoes in reading comprehension, autonomy in tefl, and learning styles. Revista de Lenguas Modernas. 
Richey, R., \& Klein, J. (2007). Design and development research: methods, strategies, and issues. Mahwah: NJ: Lawrence Erlbaum Associates.

Rossa, B., Pechenkinab, E., \& Aeschli, C. (2017). Print versus digital texts: Understanding the experimental research. Research in Learning Technology, 25(12), 70-78.

Shariffudin, R. (2007). Design of instructional materials for teaching and learning process: Theory into practice. $M E D C, 4(1), 97-105$.

Siregar, S. D., Sari, M., \& Simamora, D. F. (2020). Using application based on smartphone android "hello english" to increase students' english competency. English Education Journal, 8(1), 47 - 56.

Siripongdee, K., Pimdee, P., \& Somki. (2020, June). A blended learning model with IoT-based technology: Effectively used when the COVID-19 pandemic? Journal for the Education of Gifted, 8(2), 905-917.

Subedi, S., Nayaju, S., \& Subedi, S. (2020). Impact of e-learning during COVID-19 pandemic among nursing students and teachers of nepal. International Journal of Science and Healthcare Research, 11(4), 68-76.

WHO. (2020). Coronavirus disease (COVID-19). New York: World Health Organization.

Wiberg, N. (2015). Screen vs. paper: what is the difference for reading and learning? Insights - 28(2), 4954.

Winke , P., \& MacGregor, D. (2001). review of hot potatoes. Language Learning \& Technology, 6(2), 2833. 